\title{
PENGARUH LINGKUNGAN KERJA DAN GAYA KEPEMIMPINAN TERHADAP KINERJA KARYAWAN PADA PT PRIMA TERA INTIDATA
}

\author{
${ }^{*}$ Endang Kustini, ${ }^{2}$ Cecep Hidayat \\ Universitas Pamulang, Tangerang Selatan, Banten, Indonesia \\ *dosen01518@unpam.ac.id
}

\begin{abstract}
Abstrak
Penelitian ini bertujuan untuk mengetahui pengaruh antara Lingkungan Kerja dan Gaya Kepemimpinan terhadap Kinerja Karyawan pada PT. Prima Tera Intidata. Hipotesis penelitian yang diuji adalah terdapat signifikan antara lingkungan kerja dan gaya kepemimpinan terhadap kinerja karyawan pada PT. Prima Tera Intidata. Metode penelitian yang digunakan dalam penelitian ini adalah metode penelitian kuantitatif, metode sampling yang digunakan adalah sampel jenuh sebanyak 75 karyawan. Teknik pengumpulan data dengan angket, sedangkan metode analisa data yang digunakan uji validitas, uji reliabilitas, uji asumsi klasik, analisis regresi linier sederhana, analisis regresi linier berganda, analisis koefisien korelasi (R), analisis koefisien determinasi, dan pengujian hipotesis. Berdasarkan hasil penelitian hasil uji $\mathrm{t}$ diperoleh thitung untuk Lingkungan Kerja lebih besar dari nilai tabel 1,993 atau $(3,826>1,993)$ dengan nilai signifikan 0,000 <0,05. Maka dapat disimpulkan bahwa secara parsial Lingkungan Kerja berpengaruh positif dan signifikan terhadap Kinerja Karyawan. Hal ini berarti bahwa H0 ditolak dan H1 diterima. Nilai thitung dari Gaya Kepemimpinan lebih besar dari tabel 1,993 atau $(3,826>1,933)$ dengan nilai signifikan $0,019<0,05$. Maka dapat disimpulkan bahwa secara parsial Gaya kepemimpinan kerja berpengaruh positif dan signifikan terhadap kinerja karyawan. Hal ini berarti bahwa $\mathrm{H} 0$ ditolak dan $\mathrm{H} 1$ diterima. Untuk uji F diperoleh nilai Fhitung sebesar 29,044 dan signifikan sebesar 0,000 sehingga dapat disimpulkan antara Lingkungan Kerja dan Gaya Kepemimpinan secara simultan berpengaruh terhadap kinerja karyawan dibuktikan dengan nilai $\mathrm{f}$ hitung 29,044 $>\mathrm{f}_{\text {tabel }}$ 3,12 dan nilai signifikan $0,000<0,05$ maka dapat disimpulkan H0 ditolak dan H1 diterima. Hasil analisis linier berganda diperoleh $Y=18,454+0,204 X_{1}+0,359 X_{2}$
\end{abstract}

Kata Kunci: Lingkungan Kerja, Gaya Kepemimpinan, dan Kinerja Karyawan

This study aims to determine the effect of the work environment and leadership style on employee performance at PT. Prima Tera Intidata. The research hypothesis tested is that there is a significant relationship between work environment and leadership style on employee performance at PT. Prima Tera Intidata. The research method used in this study is a quantitative research method, the sampling method used is a saturated sample of 75 employees. The data collection technique is using a questionnaire, while the data analysis method used is validity test, reliability test, classical assumption test, simple linear regression analysis, multiple linear regression analysis, correlation coefficient analysis (R), coefficient of determination analysis, and hypothesis testing. Based on the results of the research, the $t$-test results obtained that tcount for the Work Environment is greater than the ttable value of 1.993 or $(3.826>1.993)$ with a significant value of $0.000<0.05$. So it can be concluded that partially the work environment has a positive and significant effect on employee performance. This means that $\mathrm{HO}$ is rejected and $\mathrm{H} 1$ is accepted. The $t$-count value of Leadership Style is greater than ttable 1.993 or $(3.826>1.933)$ with a significant value of $0.019<0.05$. So it can be concluded that partially work leadership style has a positive and significant effect on employee performance. This means that $\mathrm{HO}$ is rejected and $\mathrm{H} 1$ is accepted. For the F test, the Fcount value is 29,044 and a significant value of 0.000 so that it can be concluded that the Work Environment and Leadership Style simultaneously affect employee performance as evidenced by the value of $f$ count $29,044>f$ table 3.12 and a significant value of $0.000<0.05$, it can be concluded $\mathrm{HO}$ is rejected and $H 1$ is accepted. The results of multiple linear analysis obtained $Y=18,454+0,204 X 1+0,359 X 2$

Keywords: Work Environment, Leadership Style, and Employee Performance 


\section{PENDAHULUAN}

\section{Latar Belakang Masalah}

Selain Lingkungan Kerja, faktor lain yang mempengaruhi kinerja karyawan yaitu Gaya Kepemimpinan. Setiap pemimpin pada dasarnya memiliki perilaku yang berbeda dalam memimpin para pengikutnya, perilaku para pemimpin itu disebut dengan gaya kepemimpinan. Gaya Kepemimpinan merupakan suatu cara pemimpin untuk mempengaruhi bawahannya yang dinyatakan dalam bentuk pola tingkah laku atau kepribadian.

Gaya Kepemimpinan adalah pola menyeluruh dari tindakan seorang pemimpin baik yang tampak maupun yang tidak nampak oleh bawahannya (Veithzal Rivai, 2004: dalam Sudarsono 2017: 172) Gaya kepemimpinan menggambarkan yang konsisten dari falsafah, keterampilan, sifat, dan sikap yang mendasari perilaku seseorang.

PT. Prima Tera Intidata merupakan service industries yang didirikan untuk menjawab kebutuhan mitra kerja dalam framework/kerangka peningkatan pelayanan dan efisiensi, dengan tenaga yang terdidik dan pelatihan siap memberikan pelayanan kepada mitra kerja secara profesional dalam menyediakan jasa survey, instalasi maupun pemeliharaan sistem.

Berdasarkan hasil pra survey yang dilakukan melalui wawancara terhadap beberapa karyawan pada PT Prima Tera Intidata, permasalahan yang dialami saat ini yaitu lingkungan kerja yang belum dapat menunjang kegiatan perusahaan sesperti, cahaya yang kurang memadai, tata warna yang terlalu redup yang membuat kerja kurang maksimal, tidak ada peredam suara dan ruang gerak yang kurang efektif. Kinerja karyawan dapat dipengaruhi oleh lingkungan kerja, dimana apabila lingkungan kerja perusahaan baik maka kinerja karyawannya pun akan meningkat. Hal ini membuat perusahaan harus dapat meningkatkan lagi lingkungan kerjanya agar kinerja para karyawannya lebih baik dan bisa fokus untuk pelayanan yang maksimal kepada pelanggan.

Selain lingkungan kerja, kinerja karyawan juga dapat dipengaruhi oleh gaya kepemimpinan. Gaya Kepemimpinan yang baik akan dapat meningkatkan kualitas dan kinerja para karyawannya. Gaya kepemimpinan yang terdapat pada perusahaan masih terdapat gaya kepemimpinan yang kurang demokratis seperti tidak menghargai saran bawahan, selain itu pimpinan perusahaan juga masih

bersifat otoriter yang membuat karyawan harus selalu mengikuti kemauanpimpinannya tanpa diberikan keleluasaan dalam bekerja, kurang bersifat kharismatik dan paternalistic atau kurang mengayomi karyawan sehingga para karyawan masih merasa kurang didengarkan pendapatnya oleh pemimpinnya, sehingga dapat mempengaruhi kinerja karyawan dalam bekerja dan membuat perusahaan sulit untuk berkembang. lingkungan kerja pada PT. Prima Tera Intidata yaitu dimana fasilitas pendingin yang sangat terbatas, tidak semua ruangan yang mendapatkan fasilitas AC sehingga mengakibatatkan temperatur udara pada sejumlah ruangan khususnya ruangan tunggu/ruang pelayanan pelanggan menjadi lebih panas yang mengakibatkan bagian pelayanan tidak fokus dalam bekerja dan pelangganpun tidak merasa nyaman. Kemudian terkait penerangan masih ada beberapa ruangan yang penerangannya tidak mencukupi dan suasana ruangan terlihat muram, suasana kerja pada PT. Prima Tera Intidata juga sangat bising, dikarenakan tidak ada peredam suara sehingga suara bising dari ruang tunggu atau ruang pelayanan pelanggan terdengar hingga kedalam ruangan kerja pegawai dan untuk penggunaan tata warna sudah baik, akan tetapi monoton disetiap ruangan tidak bisa di ganti warna karena sudah kebijakan dari perusahaan, kemudian masih ada sebagian ruang gerak karyawan yang 
terbatas diakibatkan tata ruang yang kurang efektif yang dapat mempengaruhi kinerja karyawan. pengaruhnya tingkat kepemimpinan pada PT. Prima Tera Intidata masih terbilang belum optimal atau masih rendah, maka perlu adanya optimalisasi kembali dalam rangka meningkatkan kepemimpina PT. Prima Tera Intidata.

Sebagaimana penjelasan diatas, bahwa salah satu indikator mempengaruhi lingkungan kerja dan gaya kepemimpinan terhadap kinerja karyawan. Maka dari itu perusahaan harus terus meningkatkan dan juga menyeimbangkan indikator tersebut agar proyek berjalan sesuai dengan harapan dikarenakan kerjasama antara pimpinan dengan karyawan yang membuat konsumen puas dan menggunakan jasa perusahaan kembali untuk proyek selanjutnya.

PT. Prima Tera Intidata sumber daya manusianya memiliki satu visi, misi dan tujuan yang sama, yaitu memberikan kepuasan kepada pelanggan dan mengalami peningkatan pendapatan dari tahun ke tahun. Untuk mencapai hal tersebut tentunya diperlukan sumber daya manusia yang berkualitas agar perusahaan dapat memberikan pelayanan terbaik. Hal ini tentunya perlu adanya peran kepemimpinan yang dapat menciptakan suasana kerja yang harmonis terhadap karyawan guna meningkatkan kinerjakinejra karyawannya. Berikut adalah tabel data kinerja karyawan PT. Prima Tera Intidata.

\section{Rumusan Masalah}

a. Apakah ada pengaruh lingkungan kerja terhadap kinerja karyawan pada PT. Prima Tera Intidata?

b. Apakah ada pengaruh gaya kepemimpinan terhadap kinerja karyawan pada PT. Prima Tera Intidata?

c. Apakah ada pengaruh lingkungan kerja dan gaya kepemimpinan kerja terhadap kinerja kayawan pada PT. Prima Tera Intidata?

\section{TINJAUAN PUSTAKA}

\section{Lingkungan Kerja Fisik}

Menurut Afandi

(2018:65) menyatakan bahwa "Lingkungan kerja adalah segala sesuatu yang ada disekitar karyawan dan dapat mempengaruhi dalam menjalankan tugas yang diembankan kepadanya misalnya dengan adanya air conditioner (AC), Penerangan yang memadai dan sebagainya".

Menurut Danang (2015:38)

"lingkungan kerja adalah segala sesuatu yang ada disekitar para pekerja dan yang dapat mempengaruhi dirinya dalam menjalankan tugas-tugas yang dibebankan".

Menurut Sedarmayanti dalam Desi (2015:25) "lingkungan kerja adalah keseluruhan alat perkakas dan bahan yang dihadapi, lingkungan sekitarnya dimana seseorang bekerja, metode kerjanya, serta pengaturan kerjanya baik sebagai perseorangan maupun sebagai kelompok.

\section{Kinerja Karyawan}

Setiap manusia mempunyai potensi untuk bertindak dalam berbagai bentuk aktivitas. Kemampuan bertindak itu dapat diperoleh manusia baik secara alami (ada sejak lahir) atau dipelajari. Walaupun manusia mempunyai potensi untuk berperilaku tertentu tetapi perilaku itu hanya diaktualisasi pada saat-saat tertentu saja. Potensi untuk berperilaku tertentu itu disebut ability (kemampuan), sedangkan ekspresi dari potensi ini dikenal sebagai performane (kinerja).

Menurut Rivai dalam Busro (2018:88), "kinerja adalah kesediaan seseorang atau kelompok orang untuk melakukan sesuatu kegiatan dan menyempurnakannya sesuai dengan tanggung jawab dengan hasil seperti yang diharapkan".

Menurut Armstrong dalam Edison 
dkk (2017:188), "kinerja adalah hasil dari suatu proses yang mengacu dan diukur selama periode waktu tertentu berdasarkan ketentuan atau kesepakatan yang telah ditetapkan sebelumnya".

\section{Pengembangan Hipotesis}

a. Apakah ada pengaruh lingkungan kerja terhadap kinerja karyawan pada PT. Prima Tera Intidata?

Ho: Diduga Lingkungan Kerja tidak berpengaruh terhadap Kinerja Karyawan pada PT. Prima Tera Intidata.

Ha: Diduga Lingkungan Kerja berpengaruh terhadap Kinerja Karyawan pada PT. Prima Tera Intidata.

b. Apakah ada pengaruh gaya kepemimpinan terhadap kinerja karyawan pada PT. Prima Tera Intidata?

Ho: Diduga Gaya Kepemimpinan tidak berpengaruh terhadap Kinerja Karyawan pada PT. Prima Tera Intidata.

Ha: Diduga Gaya Kepemimpinan berpengaruh terhadap Kinerja Karyawan pada PT. Prima Tera Intidata.

c. Apakah ada pengaruh lingkungan kerja dan gaya kepemimpinan terhadap kinerja karyawan pada PT. Prima Tera Intidata?

Ho: Diduga Lingkungan Kerja dan Gaya Kepemimpinan tidak berpengaruh terhadap Kinerja Karyawan pada PT. Prima Tera Intidata.

Ha: Diduga Lingkungan Kerja dan Gaya Kepemimpinan berpengaruh terhadap Kinerja Karyawan pada PT. Prima Tera Intidata.

\section{METODOLOGI PENELITIAN Jenis Penelitian}

Jenis penelitian yang digunakan adalah jenis penelitian kuantitatif. Menurut Sugiyono (2017:11) penelitian kuantitatif adalah penelitian dengan memperoleh data yang berbentuk angka untuk menguji suatu hipotesis. Metode penelitian ini menggunakan metode asosiatif. Menutut Sugiyono (2017:121) penelitan asosiatif merupakan penelitian yang bertujuan untuk mengetahui hubungan antara dua variabel atau lebih. Dengan penelitian asosiatif ini maka akan dapat dibangun suatu teori yang dapat berfungsi untuk menjelaskan, meramalkan, dan mengontrol suatu gejala.

\section{Tempat dan Waktu Penelitian}

\section{Tempat Penelitian}

Penelitian ini dilakukan dikantor PT. Prima Tera Intidata yang berlokasi di Pondok indah office tower 3, lt. $17 \mathrm{Jl}$. Sultan Iskandar Muda Kav. V-TA, Pondok Pinang, Kebayoran Lama Jakarta Selatan 12310 ,

\section{Waktu Penelitian}

Waktu penelitian dilakukan selama 6 bulan dari Februari sampai Juli 2021, Penelitian ini dilakukan secara bertahap diambil dengan cara riset mulai dari pendahuluan, pengajuan proposal, pengajuan surat ijin, konsultasi, dan penyebaran kuesioner, hingga penarikan kuesioner.

\section{Populasi dan Sampel}

\section{Populasi}

Populasi dalam penelitian ini adalah seluruh karyawan yang bekerja pada PT. Prima Tera Intidata yang berjumlah 75 pegawai.

\section{Sampel}

Pengambilan sampel dalam penelitian ini meggunakan sampel jenuh yaitu berjumlah 75visi orang karyawan.

\section{Teknik Data}

1. Teknik Analisa Data

Uji Instrumen Penelitian

Uji Validitas Data

Uji Reliabilitas

2. Pengujian Persyaratan Analisis (Uji

Asumsi Klasik)

Uji Normalitas

Uji Multikolinieritas

Uji Heteroskedastisitas 
Uji Autokorelasi

Uji Korelasi

3. Analisis Regresi

Regresi Linear Berganda

Analisis Koefisien Determinasi
4. Rancangan Pengujian Hipotesis Pengujian Pengaruh Secara Parsial (Uji t)

Pengujian Pengaruh Secara Simultan

(Uji F)

\section{HASIL PENELITIAN DAN PEMBAHASAN}

Analisis Regresi Linier Sederhana

Tabel 1. Hasil Pengujian Regresi Linier Sederhana VariabelLingkungan Kerja (X1) Terhadap Kinerja Karyawan (Y)

\begin{tabular}{|c|c|c|c|c|c|c|}
\hline \multicolumn{7}{|c|}{ Coefficients $^{a}$} \\
\hline \multirow{2}{*}{\multicolumn{2}{|c|}{ Model }} & \multicolumn{2}{|c|}{ Unstandardized Coefficients } & \multirow{2}{*}{$\begin{array}{c}\text { Standardized } \\
\text { Coefficients } \\
\text { Beta } \\
\end{array}$} & \multirow[b]{2}{*}{$\mathrm{t}$} & \multirow[b]{2}{*}{ Sig. } \\
\hline & & $\mathrm{B}$ & Std. Error & & & \\
\hline 1 & (Constant) & 25.215 & 3.110 & & 8.108 & .000 \\
\hline & Lingkungan Kerja & .399 & .074 & .533 & 5.389 & .000 \\
\hline
\end{tabular}

Berdasarkan tabel diatas dapat dilihat perhitungan regresi linear sederhana, sehingga dapat disusun persamaan sebagai berikut: $\mathrm{Y}=\mathbf{2 5 . 2 1 5}+\mathbf{0 , 3 9 9 X _ { 1 }}$

Dari persamaan diatas,maka dapat disimpulkan sebagai berikut:

1. Nilai konstanta nilainya sebesar 25.215 yang mempunyai arti bahwa jika tidak

Tabel 2. Hasil Pengujian Regresi Linier

\begin{tabular}{|c|c|c|c|c|c|c|}
\hline \multicolumn{7}{|c|}{ Coefficients $^{\mathrm{a}}$} \\
\hline \multirow{2}{*}{\multicolumn{2}{|c|}{ Model }} & \multicolumn{2}{|c|}{ Unstandardized Coefficients } & \multirow{2}{*}{$\begin{array}{c}\text { Standardized } \\
\text { Coefficients } \\
\text { Beta } \\
\end{array}$} & \multirow[b]{2}{*}{$\mathrm{t}$} & \multirow[b]{2}{*}{ Sig. } \\
\hline & & B & Std. Error & & & \\
\hline \multirow[t]{2}{*}{1} & (Constant) & 21.366 & 3.231 & & 6.612 & .000 \\
\hline & Gaya Kepemkmpinan & .494 & .077 & .598 & 6.378 & .000 \\
\hline
\end{tabular}

Berdasarkan tabel diatas dapat dilihat perhitungan regresi linear sederhana, sehingga dapat di susun persamaan sebagai

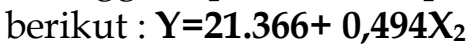

Dari persamaan diatas,maka dapat disimpulkan sebagai berikut:

1. Nilai konstanta nilainya sebesar 21.366 yang mempunyai arti bahwa jika tidak
2. ada Lingkungan Kerja (X1) maka nilai konsisten kinerja karyawan (Y) adalah sebesar 25.215

3. Angka koefisien regresi Lingkungan Kerja sebesar 0,399 artinya bahwa penambahan $1 \%$ tingkat Lingkungan Kerja (X1), maka kinerja karyawan (Y) akan meningkat sebesar 0,39.

Tabel 3. Hasil Analisis Regresi Linier Berganda

\begin{tabular}{|c|c|c|c|c|c|}
\hline \multicolumn{6}{|c|}{ Coefficients $^{\mathrm{a}}$} \\
\hline \multirow[b]{2}{*}{ Model } & \multicolumn{2}{|c|}{ Unstandardized Coefficients } & $\begin{array}{l}\text { Standardized } \\
\text { Coefficients }\end{array}$ & \multirow[b]{2}{*}{$\mathrm{t}$} & \multirow[b]{2}{*}{ Sig. } \\
\hline & B & Std. Error & Beta & & \\
\hline (Constant) & 18.454 & 3.357 & & 5.497 & .000 \\
\hline Lingkungan Kerja & .204 & .085 & 273 & 2.402 & .019 \\
\hline
\end{tabular}




\begin{tabular}{|l|r|r|r|r|r|}
\hline $\begin{array}{l}\text { Gaya } \\
\text { Kepemkmpinan }\end{array}$ & .359 & .094 & .435 & 3.826 & .000 \\
\hline
\end{tabular}

Analisis Regresi Linier Berganda

Tabel 4. Hasil Koefisien Korelasi secara Parsial antara Variabel Lingkungan Kerja (X1) Terhadap Kinerja Karyawan (Y)

\begin{tabular}{|l|l|r|r|}
\hline \multicolumn{4}{|c|}{ Correlations } \\
\hline \multirow{3}{*}{ Lingkungan Kerja } & Pearson Correlation & \multicolumn{1}{|c|}{ Lingkungan Kerja } & \multicolumn{1}{c|}{ Kinerja Karyawan } \\
\cline { 2 - 4 } & Sig. (2-tailed) & 1 & $.533^{* *}$ \\
\cline { 2 - 4 } & $\mathrm{N}$ & 75 & .000 \\
\hline Kinerja Karyawan & Pearson Correlation & $.533^{* *}$ & 75 \\
\cline { 2 - 4 } & Sig. (2-tailed) & .000 & 75 \\
\cline { 2 - 4 } & $\mathrm{N}$ & 75 & 75 \\
\hline \multirow{2}{*}{ **. Correlation is significant at the 0.01 level (2-tailed). }
\end{tabular}

Berdasarkan hasil korelasi pada tabel diatas, maka diperoleh nilai koefisien korelasi sebesar 0,533, artinya variabel

lingkungan kerja (X1) memiliki tingkat hubungan yang kuat terhadap variabel kinerja karyawan (Y).

Tabel 5. Hasil Koefisien Korelasi secara Parsial antara Variabel Gaya Kepemimpinan (X2)

Terhadap Kinerja Karyawan (Y)

\begin{tabular}{|l|l|r|r|}
\hline \multicolumn{3}{|c|}{ Correlations } \\
\hline \multirow{3}{*}{ Gaya Kepemkmpinan } & Gearson Correlation & 1 & \multicolumn{1}{|c|}{ Kinerja Karyawan } \\
\cline { 2 - 4 } & Sig. (2-tailed) & 75 & $.598^{* *}$ \\
\cline { 2 - 4 } & $\mathrm{N}$ & $.598^{* *}$ & .000 \\
\hline Kinerja Karyawan & Pearson Correlation & .000 & 75 \\
\cline { 2 - 4 } & Sig. (2-tailed) & 75 & 1 \\
\cline { 2 - 4 } & $\mathrm{N}$ & & 75 \\
\hline \multirow{2}{*}{$* *$. Correlation is significant at the 0.01 level (2-tailed). } \\
\hline
\end{tabular}

Berdasarkan hasil korelasi pada tabel diatas, maka diperoleh nilai koefisien korelasi sebesar 0,598 , artinya variabel gaya

kepemimpinan (X2) memiliki tingkat hubungan yang kuat terhadap variabel kinerja karyawan $(\mathrm{Y})$.

Tabel 6. Hasil Analisis Koefisien Korelasi Secara Simultan Antara Lingkungan Kerja (X1) dan Gaya Kepemimpinan(X2) Terhadap Kinerja Karyawan (Y)

\begin{tabular}{|l|c|c|c|c|}
\hline \multicolumn{5}{|c|}{ Model Summary } \\
\hline $\begin{array}{l}\text { Mo } \\
\text { del }\end{array}$ & $\mathrm{R}$ & $\begin{array}{c}\mathrm{R} \\
\text { Square }\end{array}$ & $\begin{array}{c}\text { Adjusted } \\
\text { R Square }\end{array}$ & $\begin{array}{c}\text { Std. Error } \\
\text { of the } \\
\text { Estimate }\end{array}$ \\
\hline 1 & $.637 \mathrm{a}$ & .405 & .389 & 2.433 \\
\hline \multicolumn{4}{|l|}{ a. Predictors: (Constant), Lingkungan Kerja } \\
\hline \multicolumn{4}{|l}{ b. Dependent Variable: Kinerja Karyawan } \\
\hline
\end{tabular}

Berdasarkan hasil pengujian pada tabel di atas, diperoleh $R$ (koefisien korelasi) sebesar 0,533 artinya variabel lingkungan kerja (X1) dan gaya kepemimpinan (X2) mempunyai tingkat pengaruh atau hubungan yang kuat terhadap kinerja karyawan $(\mathrm{Y})$. 
Koefisien Determinasi

Tabel 7. Koefisien Determinasi

\begin{tabular}{|l|r|c|r|c|r|}
\hline \multicolumn{7}{|c|}{ Model Summary $^{\mathbf{b}}$} \\
\hline Model & $\mathrm{R}$ & R Square & Adjusted R Square & $\begin{array}{c}\text { Std. Error of the } \\
\text { Estimate }\end{array}$ & Durbin-Watson \\
\hline 1 & $.637 \mathrm{a}$ & .405 & .389 & 2.433 & 1.472 \\
\hline
\end{tabular}

Berdasarkan tabel diatas diketahui nilai koefisien determinasi atau $\mathrm{R}$ square adalah sebesar 0,405 atau sama dengan 40,1\%. Angka tersebut mengandung arti bahwa variabel lingkungan kerja (X1) dan gaya kepemimpinan (X2) berpengaruh terhadap variabel kinerja karyawan $(Y)$ sebesar 40,1\% sedangkan sisanya 59,9\% dipengaruhi oleh variabel lain diluar variabel yang tidak diteliti.

\section{Uji Hipotesis}

\section{1) Uji T (Parsial)}

Tabel 8. Hasil Uji Hipotesis (Uji T)

\begin{tabular}{|c|c|c|c|c|c|c|}
\hline \multicolumn{7}{|c|}{ Coefficients $^{\mathrm{a}}$} \\
\hline & & \multicolumn{2}{|c|}{$\begin{array}{c}\text { Unstandardized } \\
\text { Coefficients }\end{array}$} & \multirow{2}{*}{$\begin{array}{c}\begin{array}{c}\text { Standardized } \\
\text { Coefficients }\end{array} \\
\text { Beta }\end{array}$} & \multirow[b]{2}{*}{$t$} & \multirow[b]{2}{*}{ Sig. } \\
\hline \multicolumn{2}{|c|}{ Model } & $\mathrm{B}$ & Std. Error & & & \\
\hline \multirow[t]{3}{*}{1} & (Constant) & 18.454 & 3.357 & & 5.497 & .000 \\
\hline & Lingkungan Kerja & .204 & .085 & .273 & 2.402 & .019 \\
\hline & Gaya Kepemkmpinan & .359 & .094 & .435 & 3.826 & .000 \\
\hline
\end{tabular}

Berdasarkan tabel diatas dapat dilihat hasil data yang telah diolah, dapat dijelaskan tentang pengaruh variabel independen terhadap variabel dependen seperti berikut ini:

1) Pengaruh Lingkungan Kerja (X1) terhadap Kinerja Karyawan (Y)

Berdasarkan hasil analisis pada tabel diatas diperoleh nilai $t_{\text {hitung }}>$ $t_{\text {tabel }}$ atau $(2,402>1,993)$ hal ini diperkuat dengan nilai signifikansi $0,019<0,05$ berdasarkan hasil pengujian yang diperoleh maka $\mathrm{H}_{0}$ ditolak dan $\mathrm{H}_{1}$ diterima. Artinya secara parsial variabel lingkungan kerja berpengaruh positif dan signifikan terhadap kinerja karyawan.

2) Pengaruh Gaya Kepemimpinan (X2) terhadap Kinerja Karywan (Y)

Berdasarkan hasil analisis pada tabel diatas diperoleh nilai thitung $>$ $t_{\text {tabel }}$ atau $(3,826>1,993)$ hal ini diperkuat dengan nilai signifikansi $0,000<0,05$ berdasarkan hasil pengujian yang diperoleh maka $\mathrm{H}_{0}$ ditolak dan $\mathrm{H}_{1}$ diterima. Artinya secara parsial variabel disiplin kerja berpengaruh positif dan signifikan terhadap kinerja karyawan.

\section{2) Uji F (Simultan)}

Tabel 9. Hasil Uji Hipotesis (Uji F)

\begin{tabular}{|c|c|c|c|c|c|c|}
\hline \multicolumn{7}{|c|}{ ANOVA $^{a}$} \\
\hline \multicolumn{2}{|c|}{ Model } & Sum of Squares & $\mathrm{df}$ & Mean Square & $\mathrm{F}$ & Sig. \\
\hline \multirow[t]{3}{*}{1} & Regression & 204.116 & 1 & 204.116 & 29.044 & $.000^{\mathrm{b}}$ \\
\hline & Residual & 513.031 & 73 & 7.028 & & \\
\hline & Total & 717.147 & 74 & & & \\
\hline
\end{tabular}


Berdasarkan hasil analisis pada tabel diatas diperoleh nilai $\mathrm{f}_{\text {hitung }}>\mathrm{f}_{\text {tabel }}$ atau $(29,044>3,12)$ hal ini diperkuat dengan nilai signifikansi $0,000<0,05$ berdasarkan hasil pengujian yang diperoleh maka $\mathrm{H}_{0}$ ditolak dan $\mathrm{H}_{1}$ diterima secara simultan variabel lingkungan kerja dan gaya kepemimpinan berpengaruh positif dan signifikan terhadap kinerja karyawan.

\section{KESIMPULAN DAN SARAN}

\section{Kesimpulan}

1. Variabel lingkungan kerja (X1) berpengaruh positif dan signifikan terhadap kinerja karyawan dengan tingkat hubungan yang diperoleh nilai $t_{\text {hitung }}=(2,402>1,993)$ hal ini diperkuat dengan nilai signifikansi $0,019<0,05$ berdasarkan hasil pengujian yang diperoleh maka $\mathrm{H}_{0}$ ditolak dan $\mathrm{H}_{1}$ diterima. Artinya adalah varaibel lingkunga kerja berpengaruh positif dan signifikan terhadap kinerja karyawan pada PT. Prima Tera Intidata.

2. Variabel gaya kepemimpinan (X2) berepngaruh positif dan signifikan terhadap kinerja karyawan yang diperoleh nilai $t_{\text {hitung }}>t_{\text {tabel }}$ atau (3.826 $>$ 1,993) hal ini diperkuat dengan nilai signifikansi $0,000<0,05$ berdasarkan hasil pengujian yang diperoleh maka $\mathrm{H}_{0}$ ditolak dan $\mathrm{H}_{1}$ diterima. Artinya adalah variabel lingkungan kerja berpengaruh positif dan signifikan terhadap kinerja karyawan pada PT. Prima Tera Intidata.

3. Variabel lingkungan kerja (X1) dan gaya kepemimpinan (X2) berpengaruh positif dan signifikan terhadap kinerja karyawan. Berdasarkan hasil analisis pada tabel nilai fhitung $>$ ftabel atau $(29.044>3,12)$ hal ini diperkuat dengan nilai signifikansi $0,000<0,05$ berdasarkan hasil pengujian yang diperoleh maka $\mathrm{H} 0$ ditolak dan $\mathrm{H} 1$ diterima. Artinya secara simultan variabel lingkungan kerja dan gaya kepemimpinan berpengaruh positif dan signifikan terhadap kinerja karyawan pada PT. Prima Tera Intidata

\section{Saran}

1. Lingkungan kerja di PT. Prima Tera Intidata sudah mulai membaik terutama dalam hal penerangan, ruang gerak sudah mulai ada perbaikan, maka peneliti dapat memberikan saran supaya perusahaan harus dapat mempertahankan dan meningkatkan lagi penerangan atau pencahayaan didalam lingkungan kerja

2. Gaya kepemimpin di PT. Prima Tera Intidata sudah mulai baik terutama dalam hal laize faire, maka peneliti dapat memberikan saran kepada pemimpin perusahaan untuk tidak terlalu mengambil keputusan secara sepihak, memberikan kebebasan kepada karyawannya dalam bekerja gar karyawan tetap memiliki tanggung jawab dalam pekerjaannya.

3. Kinerja karyawan di PT. Prima Tera Intidata sudah baik terutama dalam hal kualitas kerja, maka peneliti dapat memberikan saran untuk perusahaan agar menjaga kualitas kerja karyawannya dan supaya perusahaan juga dapat terus meningkatkan kualitas kerja karyawannya agar dapat lebih baik lagi ke depannya.

\section{DAFTAR PUSTAKA}

Abdullah, Ma'ruf. 2014. Manajemen dan Evaluasi Kinerja Karyawan. Penerbit Aswaja Pressindo. Yogyakarta.

Amirullah, (2015). Pengantar Manajemen. Jakarta: Mitra Wacana Media.

Bintoro, M.T., \& Daryanto. (2017 ). Manajemen Penilaian Kinerja Karyawan.Yogyakarta: Penerbit Gava Media.

Dessler. (2015), Manajemen Sumber Daya Manusia. Jakarta: Salemba Empat.

Edy, Sutrisno, (2016), Manajemen Sumber Daya Manusia, Kencana Prenada Media Group, Jakarta.

Edy, Sutrisno. 2016. Manajemen Sumber Daya Manusia. Cetakan ke-8. Jakarta : Prenada Media Group

Edy, Sutrisno. 2017. Manajemen Sumber Daya Manusia, Edisi Ke-9, Kencana, Jakarta. 
Gaol L, jimmy, 2014. A to Z Human Capital: Manajemen Sumber daya Manusia. Jakarta:PT Grasindo

Ghozali, 2014. Aplikasi analisis Multivariate dengan Program SPSS. Badan Penerbit UNDIP , Semarang.

Ghozali, Imam. 2011. "Aplikasi Analisis Multivariate Dengan Program SPSS". Semarang: Badan Penerbit Universitas Diponegoro.

Ghozali, Imam. 2013. Aplikasi Analisis Multivariate dengan Program IBM SPSS 21 Update PLS Regresi. Semarang: Badan Penerbit Universitas Diponegoro.

Ghozali, Imam. 2016. Aplikasi Analisis Multivariete Dengan Program IBM SPSS 23 (Edisi 8). Cetakan ke VIII. Semarang : Badan Penerbit Universitas Diponegoro.

Hamali, A. Y. (2016). Pemahaman Manajemen Sumber Daya Manusia: Strategi Mengelola Karyawan. Yogyakarta: CAPS (Center for Academic Publishing Service).

Hasibuan, 2017, Manajemen Sumber Daya Manusia, Jakarta: PT Bumi Aksara

Hasibuan, M, SP. 2016. Manajemen Sumber Daya Manusia. Jakarta: Edisi Revisi, Bumi Aksara.

Hasibuan, Malayu S.P. 2014. Pengertian Manajemen Sumber Daya Manusia , Fungsi SDM , Pengawasan. Edisi Revisi. Jakarta: Bumi Aksara

Hasibuan, Malayu SP. (2014). Manajemen Sumber Daya Manusia, Cetakan keempatbelas, Jakarta ,Penerbit : Bumi Aksara.

Hermawati, R., et al. (2021). Pengaruh Pelatihan Dan Motivasi Terhadap Kinerja Karyawan Pada Bank BJB di Cabang Balaraja Banten. JENIUS (Jurnal Ilmiah Manajemen Sumber Daya Manusia), 4(3), 319-331.

Koesmowidjojo Suci R. Ma'arih. 2017. Panduan Praktis Menyusun
Analisis Beban Kerja. Jakarta. Raih

Asa.

Nurjaya, N., et al.. (2021). Pengaruh Brand Image Terhadap Keputusan Pembelian Pada PT. Wahana Motor Di Wilayah Cianjur. Jurnal Ilmiah PERKUSI, 1(2), 291-296.

Sugiyono. (2016). Metodologi Penelitian Kuantitatif, Kualitatif, dan R\&D. Bandung: CV Alfabeta.

Sugiyono. 2015. Metode Penelitian Kuantitatif. Kualitatif dan RED. Bandung Alfabeta.

Sugiyono. 2017. Metode Penelitian Kuantitatif, Kualitatif dan RED. Bandung: Alfabeta.

Sundoro Yekti. (2012). Pengaruh Gaya Kepemimpinan, Motivasi, dan Disiplin Kerja Terhadap Kinerja Karyawan dikantor Sekretariat Daerah Kabupaten Kutai Timur. Jurnal Paradigma ISSN: 2252-4266, 1(3). Suparyadi. 2015. Manajemen Sumber Daya Manusia, Menciptakan Keunggulan Bersaing Berbasis Kompetisi SDM. Jakarta: Andi

Suwanto, S., et al.. (2021). Pengaruh Motivasi Dan Pengalaman Kerja Terhadap Produktivitas Karyawan Pada Happy Restaurant Di Bandung. Jurnal Ekonomi Efektif, 3(4), 546-554.

Tohardi, A. (2018). Pemahaman Praktis Manajemen Sumber Daya Manusia, Universitas Tanjung Pura, Mandar Maju, Bandung.

Wibowo, Eko, Suparno. 2016. Manajemen Kinerja Edisi Kelima. Jakarta: Rajawali Pers

Widodo. 2015. Manajemen Pengembangan Sumber Daya Manusia. Pustaka Pelajar, Yogyakarta.

Widodo. M.M. Suparno Eko, (2015). "Manajemen Pengembangan Sumber Daya Manusia". Cetakan II , Yogyakarta: Pustaka pelajar. 